\title{
Biodegradation of Petroleum Gasoline and High Speed Diesel Oil
}

\author{
Shailesh N Gadhvi \\ Department of Chemistry, India \\ *Corresponding Author: Dr. Shailesh N Gadhvi, Department of Chemistry, India.
}

Received: June 11, 2019; Published: July 12, 2019

DOI: 10.31080/ASMI.2019.02.0308

\begin{abstract}
Fuel is the most dynamic chemical for growth of country as well human simultaneously it is the major pollutant among various dominant pollutant. Hazardous effect of pollutant over environment depends on intrinsic biodegradability of various compositional hydrocarbon of the fuel. Such a biodegradability of fuel like petroleum diesel and gasoline can be determine using some reference aerobic Microflora that can be achieved from waste water that crated by urban during domestic use of water. Among diesel and gasoline, Gasoline exhibited a high intrinsic biodegradability (96\%) but that of a commercial diesel shows only $70 \%$. The repeating hydrocarbons of fuels were cycloalkanes and branched alkanes, the composition in terms of various hydrocarbon structural classes responsible for the diverse biodegradation rates observed. In case of linear hydrocarbon like alkane, the biodegradation rate was found close to $100 \%$. Capability of fuel biodegradation is depending on wide range of parameter that was tested here by using Microflorae. Among Microflorae of polluted soil and no polluted one from polluted soil having more efficiency for biodegradability. When Micro florae taken from polluted soil it proceed through various mechanism.
\end{abstract}

Keywords: Biodegradation; Petroleum; Diesel Oil

\section{Introduction}

Fuels are percolating in the ground state of soil due to of leaks of storage tanks and sometime defectiveness in transferring line of fuel. Such a stream of the fuels are proved crucial for the environment protection. There for it is important to do Biodegradation studies as it help us to understand in advanced the possible risks of fuel and also aid to define the most appropriate strategy to overcome this.

Various component of fuel released in the environment with the magnitude widely depends on the biodegradability of the component of hydrocarbons, using microflorae which is suitable for biodegradation and on various environmental factors. In this way, biodegradation studies are very much useful since they allow to identify the potential of microflorae for the natural degradation of fuel. At present, natural attenuation is regarded as a very efficient approach fro bioremediation. It is not used as proper cleanup alternative because it requires some action like site evaluation and contaminant migration towards sensitive dumping places such as wells or nearby situated lands. The estimation of the bioremediation potential of a polluted site is very much essential to decide natural attenuation which help to decide the cheapest remediation methodology. Several steps are useful to evaluate probability for natural attenuation at a site. The first step related to the properties and characteristics of the pollutant is its intrinsic biodegradability. For biodegradation of some commercial compounds, microflorae having wide biodegradation range. The microflorae that use for such a purpose is taken from an activated sludge which accumulate during urban wastewater treatment. In these study, with the help of $\mathrm{O}_{2}$ consumption or by $\mathrm{CO}_{2}$ production biodegradation rate can be measured. By comparing this obtain data one can easily compared biodegradation rates of readily biodegradable products, e.g. glucose, or a n-alkane such as hexadecane in case of petroleum products degradation. While the second step is useful to know natural attenuation potential which indicates biodegradation capacities of Microflora. An interesting comparative study of the local microflora with a reference microflora, i.e. an activated sludge, In this way, several parameters must be taken into account: temperature, $\mathrm{pH}$ nutrient and electron acceptor availability, water content of soil, transfer limitations in the soil matrix, in particular for dioxygen and pollutant.

The most water-insoluble components of gasoline, e.g. benzene, ethylbenzene, toluene, and xylene isomers, hydrocarbons usually termed as BTEX, have been clearly assessed using pure strains. Biodegradability of BTEX was checked using micro florae. Information 
about biodegradation of most of gasoline component is not available except some straight chain alkane conjugated benzene and some branched alkane. Kinetic of biodegradation is further modified by interactions between individual strains. Many scientist have studied the degradation of petroleum diesel oils. Among various experiment biodegradation carried out by soil microcosms reported the incomplete degradation of petroleum diesel oil.

In current study, we will focused on biodegradability of gasoline and diesel oil for purpose to get enough information on identifiable hydrocarbons or structural hydrocarbon classes during biodegradation by using various microflorae from the environment.

\section{Hydrocarbon nature of petroleum fuels}

Hydrocarbon content of both the fuel diesel and gasoline is completely different. The number of carbon chain present in gasoline is in between 4 and 10. It has distillation profile is from 30 $35^{\circ} \mathrm{C}$ to $180-200^{\circ} \mathrm{C}$. While the number of carbon chain present in diesel is in between 11 and 25 and the distillation profile range is between 180 to $380^{\circ} \mathrm{C}$.

Gasoline and diesel oil do not have any measure amounts of alkenes. They are both contained four main structural classes of hydrocarbons:

- n-alkanes (linear saturated hydrocarbons);

- Isoalkanes (branched saturated hydrocarbons);

- $\quad$ Cycloalkanes (saturated cyclic alkanes);

- Aromatics.

Gasoline having about $50 \%$ aromatic content of the total types of hydrocarbon content. Iso alkanes content is about $35 \%$. And other class of hydrocarbon like Alkanes, alkenes and cycloalkanes are found in very minor proportion. There are total 230 different type of hydrocarbons are present in gasoline composition. Such a various type of hydrocarbons can be separated and identified by analytical instrument namely gas chromatography. While in diesel oil about2000 to 4000 hydrocarbons, which are difficult to separate by gas chromatography. Although few $\mathrm{n}$ - alkanes and a few branched hydrocarbons can be identified as separated compounds. Separation of the main structural hydrocarbon classes can be carried out by using a standard procedure using analytical instrument namely high performance liquid chromatography.

\section{Methodological approach for biodegradation studies}

The biodegradability of unleaded gasoline and diesel oil can be done by test which is recommended by OECD (1993). The tests is performed with specific parameter, i.e. Temperature, Concerning
$\mathrm{pH}$, Substrate concentration, Nutrient supply and oxygen availability. The tests is done in closed systems so one can do assessment of the carbon balance at the end of incubation period. The kinetics of biodegradation were measured for determining the end point of experiment. This testing was done on concept by either on di oxygen consumption by using instrument like electrolytic respirometry or carbon dioxide production testing by using gas chromatography. Once incubation period get finished, the residual hydrocarbons were quantified and the degradation rates were determined by comparing with hydrocarbons of abiotic control flasks in which microbial growth was inhibited by $\mathrm{HgCl}_{2}$ addition.

Biodegradation of fuels by a microflora from an activated sludge

As previously indicated, the biodegradation characteristic of a commercial compound like gasoline by a microflora collected from urban waste water treatment plant, help us to know good initial approximation of its intrinsic biodegradability. Because of this, the activated sludge micro flora decided as a reference microflora.

\begin{tabular}{|l|c|c|}
\hline \multicolumn{1}{|c|}{ Hydrocarbon class } & $\begin{array}{c}\text { Degradation } \\
\text { rate }^{*} \mathbf{( \% )}\end{array}$ & $\begin{array}{c}\text { Resistant } \\
\text { fraction** }\end{array}$ (\%) \\
\hline$n$-alkanes & 100 & 0 \\
\hline Methyl- and dimethylalkanes & 98.3 & 0.5 \\
\hline Trimethylalkanes & 51.3 & 2.8 \\
\hline Cycloalkanes & 99.7 & 0 \\
\hline BTEX & 99.9 & 0 \\
\hline Other aromatics & 98.8 & 0.2 \\
\hline Alkenes & 100 & 0 \\
\hline Total gasoline & 96.5 & 3.5 \\
\hline
\end{tabular}

Table 1: Biodegradation of gasoline by the reference microflora.

In above table we can see the data for degradation rates of the major hydrocarbon classes of gasoline by using the reference microflora from activated sludge. This microflora having tendency to degrade gasoline (up to 96\%). All n- alkanes, like cycloalkanes, aromatics were totally consumed. The main repeating hydrocarbons belonged to the class of methylated alkanes. In specially, about $50 \%$ of initial trimethyl alkanes resisted to microbial degradation. Analytical study using instrument like Gas chromatography shown that the molecular recalcitrant structures were either branched hydrocarbons with a quaternary carbon or hydrocarbons with methyl groups on consecutive carbon atoms. As far concern to diesel oil degradation, the initial problem is the analytical complexity related to the huge number of components. As an example, the chro- 
matographic separation profile of the commercial diesel oil used is shown in Figure. Such a profile displayed a enough satisfactory resolution for all $\mathrm{n}$ alkanes.

At the end of the incubation period, the profile of hydrocarbons showed that all $\mathrm{n}$ - alkanes were totally consumed by the reference microflora.
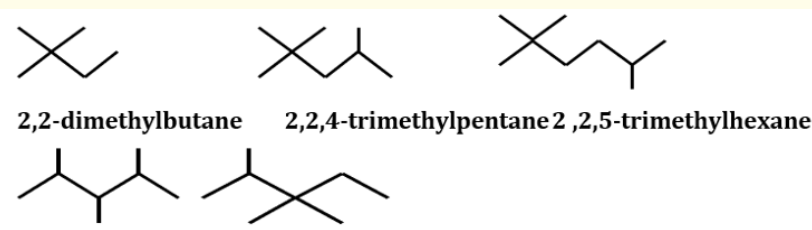

2,3,4-trimethylpentane

2,3,3-trimethylpentane

Figure a

Initially procedure used for commercial diesel oil was implemented for measuring the degradation rates of various types of diesel oils that shown in following table. Result show that the commercial diesel oil was not entirely biodegradable. Furthermore, the response to biodegradation of other diesel oils was found depending on the molecular structure like in the case of gasoline. Hydrocracking diesel oil was found slightly less biodegradable than straight run diesel due to presence of the branched structures of the constituting hydrocarbons.

\begin{tabular}{|l|c|c|}
\hline \multicolumn{1}{|c|}{ Diesel oil type } & $\begin{array}{c}\text { Degradation } \\
\text { rate (\%) }\end{array}$ & $\begin{array}{c}\text { Mineralisation } \\
\text { rate }^{* *}(\mathbf{\%})\end{array}$ \\
\hline Commercial & 73 & 62 \\
\hline Straight run & 83 & 47 \\
\hline Hydrocracking & 77 & 55 \\
\hline Fischer-Tropsch & 98 & 60 \\
\hline Rapeseed methyl esters & 100 & 79 \\
\hline Synthetic ${ }^{*}$ & 99 & 62 \\
\hline Commercial & 73 & 62 \\
\hline Straight run & 83 & 47 \\
\hline
\end{tabular}

Table 2: Degradation of various types of diesel oil by the reference microflora.

Degradation capacities of microflorae from the environment

The gasoline degradation capacities of several microflorae of the environment were tested in comparison with those of the reference microflora. Two nonpolluted-soil microflorae and 6 pollutedsoil microflorae were tested (Table 3).
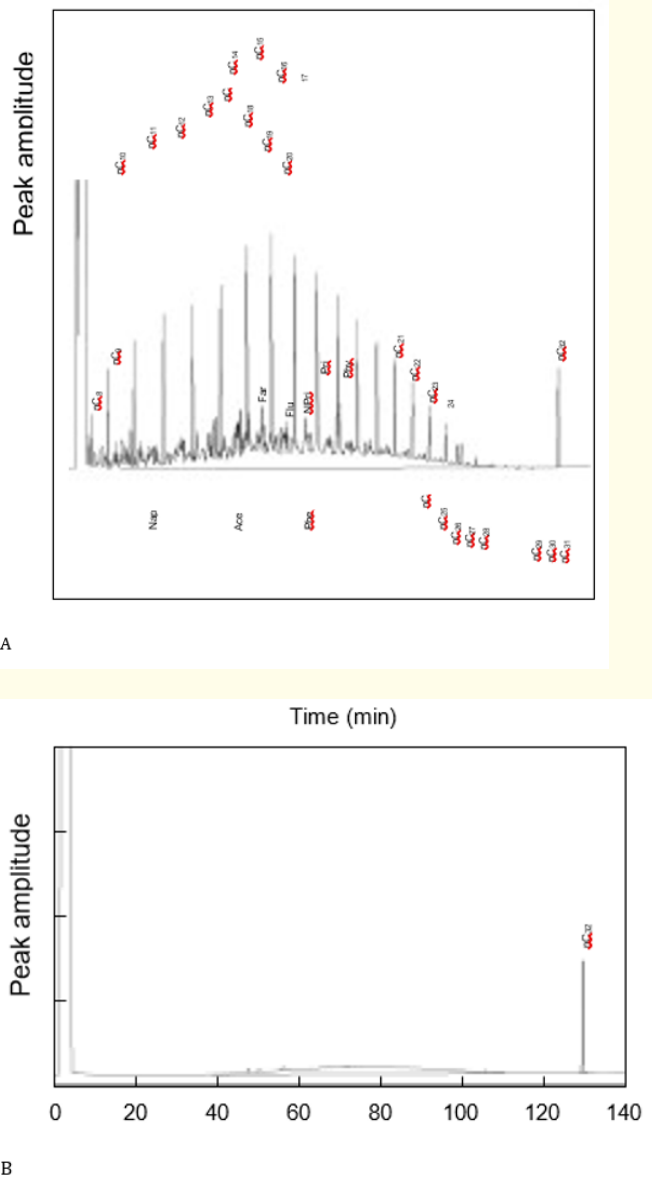

Figure 1

The hydrocarbon degradation rates observed with non polluted soils were found slightly lower side than with the reference microflora, in particularly, for cycloalkanes that displayed incomplete biodegradation. While the degradation rates measured with polluted soils were generally found higher than that of the reference microflora. Even it shows trimethyl alkanes were consumed by the polluted-soil microflorae. The degradation capacities of microflorae from the environment were similarly assayed on diesel oil (Table 4).

Two microflorae (microflorae 1 and 2) from different wastewater treatment plants shows different degradation capacities. The degradation characteristics of the refinery sludge where close to those of microflora 2 whereas those of the nonpolluted soil were found close to those of microflora 1 . With the polluted soil, the level of biodegradation was higher than with the nonpolluted soil. In this case, a quite moderate mineralization rate was calculated. This rate seemed to indicate that intermediary metabolites could accumulate as a result of an incomplete degradation of the substrate. 


\begin{tabular}{|l|c|c|c|c|c|c|}
\hline \multirow{2}{*}{\multicolumn{1}{|c}{ Microflora }} & \multicolumn{5}{|c|}{ Degradation rate (\%) for: } \\
\cline { 2 - 7 } & $\boldsymbol{n}$-alkanes & $\begin{array}{c}\text { Mono- and } \\
\text { dimethylalkanes }\end{array}$ & Trimethylalkanes & Cycloalkanes & Aromatics & Total \\
\hline Activated sludge & 100 & 100 & 27 & 100 & 100 & 95 \\
\hline Spruce forest soil & 100 & 92 & 14 & 29 & 98 & 89 \\
\hline Garden soil & 99 & 100 & 28 & 75 & 100 & 94 \\
\hline Diesel oil-polluted soil & 100 & 100 & 100 & 100 & 100 & 100 \\
\hline Jet fuel-polluted soil & 100 & 96 & 17 & 100 & 85 & 85 \\
\hline Gasoline-polluted soil & 100 & 100 & 100 & 100 & 100 \\
\hline
\end{tabular}

Table 3: Gasoline degradation capacities of microflorae from the environment.

\begin{tabular}{|l|c|c|}
\hline \multicolumn{1}{|c|}{ Microflora } & $\begin{array}{c}\text { Biodegradation } \\
\text { rate }^{*}(\mathbf{\%})\end{array}$ & $\begin{array}{c}\text { Mineralisation } \\
\text { (\%) }\end{array}$ \\
\hline Urban activated sludge 1 & 62 & 58 \\
\hline Urban activated sludge 2 & 73 & 63 \\
\hline Refinery activated sludge & 75 & 68 \\
\hline Nonpolluted soil & 65 & 58 \\
\hline Polluted soil & 92 & 56 \\
\hline
\end{tabular}

Table 4: Degradation capacities of various microflorae for commercial diesel oil.

Mechanisms of recalcitrant hydrocarbons degradation

The repetition of some hydrocarbon classes of fuels using nonpolluted-soil microflorae showed the relation of microorganisms having specialized metabolic capacities in order to achieve a highest consumption of fuels. In polluted environments, the selective pressure resulting from pollution appeared to increase soils with bio degraders of cyclic or branched hydrocarbons. Actually, microflorae having specialty in degrading cycloalkanes or an isoalkane such as isooctane were obtained from polluted environments. Using an isooctane-degrading microflora, a pure strain was isolated. This strain and its specific properties quite well explained and exampled the main mechanisms prevailing in the degradation of recalcitrant hydrocarbons in the environment. These mechanisms are the metabolism and strain cooperation.

The final balance of isooctane degradation is shown in (Table 5). The degradation data explain that more than $50 \%$ of the initial carbon was recovered in cell biomass plus $\mathrm{CO}_{2}$. This clearly indicate that M. austroafricanum had the capacity to degrade the quaternary carbon atoms. Another interesting dynamicity of this specialized microorganismis the $\beta$ - hydroxyacyl dehydrogenase this is because tertiary alcohols cannot be dehydrogenated. Since $M$. austroafricanum can grow on anteiso- methyl alkanes, it involved a metabolic pathway which can allowing $\beta$ - oxidation to proceed. This pathway could involve a decarboxylase methylation step it has been already demonstrated in other microorganisms. Metabolism ability of M. austroafricanum were demonstrated for cyclohexane degradation. M. austroafricanum was not able to utilize cyclohexane as a sole carbon source. However, when isooctane was treated and provided to the microorganism, cyclohexane was oxidized into cyclohexanone which accumulated. This M. austroafricanum could co metabolize cyclohexane when an energy substrate was available. A strain of Acinetobacter lwoffii was isolated for its capacity to degrade cyclohexane. It did not degrade cyclohexanone. When $M$. austroafricanum and A. Iwoffii were cultivated simultaneously on cyclohexanone, cyclohexane was degraded but no cyclohexanone accumulated. Measurements of final $\mathrm{CO}_{2}$ in the culture headspace showed that cyclohexane was totally mineralised. This illustrated the positive cooperative effect between the two strains for cyclohexane mineralisation. [1-26].

\section{Conclusion}

Using activated sludge Microflorae estimation about biodegradability of fuels can be carried out in flask tests. This test in case of gasoline gives very relative result with several microflorae. However, in the case of diesel oil, the relative study does not complies that much this is due to slightly different biodegradation rates of diesel. These variations is on account of differences in biodegradation capacities for branched alkanes which were present in large amounts in diesel oil compare to gasoline. Because of this gasoline was found highly biodegradable. About $97 \%$ of initial gasoline was degraded during the 27-day tests. In gasoline there were 96 major components, out of them 72 were completely degraded and remaining 28 were partially consumed. In case of diesel oil it is not much more biodegradable than gasoline. All simple straight chain n-alkanes and lighter hydrocarbons were degraded rapidly but some heavy branched hydrocarbons were not undergo biodegradation easily.

Degradation of recalcitrant structure hydrocarbons of fuel includes microorganisms having specific metabolic capacities. In polluted environments, specific microorganisms are found in profuse amount because of the adaptation of the microflorae to pollutant. 
Working efficiency of this can be enhanced by two main mechanisms. The first one is the microorganism way by which a strain oxidize repetitive hydrocarbons when an energy source is available. The second one is just cooperation between strains. This two mechanisms explain why soil microflorae have extra ordinary capacities to eliminate pollution crated by fuel from contaminated environments.

\section{Bibliography}

1. Alvarez PJJ and Vogel TM. "Substrate interaction of benzene, toluene and para- xylene during microbial degradation by pure cultures and mixed aquifer slurries". Applied and Environmental Microbiology 57.10 (1991): 2981-2985.

2. Chapelle FH. "Bioremediation of petroleum hydrocarboncontaminated ground water: the perspectives of history and hydrology". Ground water 37(1999): 122-132.

3. Council on Environmental Quality Contamination of ground water by toxic organic chemicals. Washington, D.C. Government Printing Office (1981).

4. Di Lecce C., et al. "Isolation and metabolic characterization of a Pseudomonas stutzeri mutant able to grow on the three isomers of xylene". Microbiology 63 (1997): 3279-3281.

5. Durand JP. "Le rôle de la CPG dans l'industrie pétrolière et la pétrochimie. De l'analyse détaillée des hydrocarbures à la distillation simulée". Analusis 26 (1998): M17-M21.

6. Durand JP., et al. "Detailed characterization of petroleum products with capillary analyzers". Analusis 23 (1995): 481483.

7. Fall RR., et al. "Enzyme recruitement allows the biodegradation of recalcitrant branched hydrocarbons by Pseudomonas citronellonis". Applied Microbiology and Biotechnology 38.4 (1979): 715-722.

8. Freijer JI., et al. "Assessing mineralization rates of petroleum hydrocarbons in soils in relation to environmental factors and experimental scale". Biodegradation 7.6 (1996): 487500 .

9. Gallego JLR., et al. "Bioremediation of diesel contaminated soils; evaluation of potential in situ techniques by study of bacterial degradation". Biodegradation 12.5 (2001): 325335.
10. Guibet JC. "Carburants et moteurs, Éditions Technip, Paris (1997): 21-70.

11. Lang E. "Diversity of bacterial capabilities in utilizing alkylated benzenes and other aromatics compounds". Letters in Applied Microbiology 23.4 (1996): 257-260

12. Leahy JG and Olsen RH. "Kinetics of toluene degradation by toluene-oxidizing bacteria as a function of oxygen concentration, and the effect of nitrate". FEMS Microbiology Ecology 23.1 (1997): 23-30

13. Mallakin A and Ward OP. "Degradation of BTEX compounds in liquid media and in peat biofilters". Journal of Industrial Microbiology and Biotechnology 16.5 (1996): 309-318.

14. Marquez-Rocha FJ., et al. "Biodegradation of diesel oil in soil by a microbial consortium". Water Air and Soil pollution 128.3-4 (2001): 313-320.

15. Matteau Y and Ramsay B. "Active biofiltration of toluene". Biodegradation 8.3 (1997): 135-141.

16. OECD “Guidelines for the testing of chemicals". In: Les éditions de l'OCDE, Paris 2 (1993): 1-13.

17. Olson JJ., et al. "Biodegradation rates of separated diesel components". Environmental Toxicology and Chemistry 18.11 (1999): 2448-2453.

18. Paje MLF., et al. "A Rhodococcus species that thrives on medium saturated with liquid benzene". Microbiology 143.9 (1997): 2975-2981.

19. Rozkov A., et al. "Biodegradation of dissolved jet fuel in chemostat by a mixed bacterial culture isolated from heavy polluted site". Biodegradation 8.6 (1998): 363-369.

20. Schaeffer TL., et al. "Microbial growth on hydrocarbons; terminal branching inhibits biodegradation". Biodegradation 38.4 (1979): 742-746.

21. Seklemova E., et al. "Biostimulation-based bioremediation of diesel fuel: field demonstration". Biodegradation 12.5 (2001): 311-316.

22. Solano-Serena F., et al. "Assessment of intrinsic capacities of microflorae for gasoline degradation". In: In situ and onsite bioremediation, Symp. 5th, Battelle Press, Columbus, Ohio (1999a): 177-182. 
Biodegradation of Petroleum Gasoline and High Speed Diesel Oil

23. Solano-Serena F., et al. "Biodegradation of gasoline: kinetics, mass balance, fate of individual hydrocarbons". Journal of Applied Microbiology 86.6 (1999b): 1008-1016.

24. Solano-Serena F., et al. "A new Mycobacterium strain with extended degradation capacities for gasoline hydrocarbons". Applied Environmental Biotechnology 66.6 (2000a): 23922399.

25. Solano-Serena F., et al. "Biodegradability of volatile hydrocarbons of gasoline". Applied Microbiology and Biotechnology 54.1 (2000b): 126-132.

Volume 2 Issue 8 August 2019

(c) All rights are reserved by Shailesh N Gadhvi. 